\title{
Optimization of dual energy computed tomography post-processing to reduce lower limb artifacts in gout
}

\author{
Baptiste Dubief ${ }^{1}$, Julien Avril ${ }^{2}$, Tristan Pascart ${ }^{3,4}$, Marie Schmitt ${ }^{1}$, Romaric Loffroy ${ }^{2}$, \\ Jean-Francis Maillefert ${ }^{1,5}$, Paul Ornetti ${ }^{1,5,6}$, André Ramon ${ }^{1}$ \\ ${ }^{1}$ Rheumatology Department, Dijon-Bourgogne University Hospital, Dijon, France; ${ }^{2}$ Diagnostic and Therapeutic Radiology Department, Dijon- \\ Bourgogne University Hospital, Dijon, France; ${ }^{3}$ Rheumatology Department, Lille Catholic Hospitals, University of Lille, Lomme, France; ${ }^{4}$ EA \\ 4490, PMOI, Physiopathologie des Maladies Osseuses Inflammatoires, University of Lille, Lille, France; ${ }^{5}$ INSERM UMR1093-CAPS, Université \\ Bourgogne, UFR des Sciences du Sport, Dijon, France; ${ }^{6}$ CIC-P, Plurithematic Module, Technological Investigation Platform, Dijon-Burgundy \\ University Hospital, Dijon, France
}

Contributions: (I) Conception and design: B Dubief, A Ramon, P Ornetti; (II) Administrative support: A Ramon, P Ornetti, JF Maillefert; (III) Provision of study materials or patients: J Avril, R Loffroy, B Dubief, A Ramon, M Schmitt, P Ornetti, JF Maillefert; (IV) Collection and assembly of data: B Dubief, J Avril, A Ramon, MS; (V) Data analysis and interpretation: B Dubief, A Ramon, T Pascart; (VI) Manuscript writing: All authors; (VII) Final approval of manuscript: All authors.

Correspondence to: André Ramon, MD. Rheumatology Department, Dijon University Hospital, 14 rue Paul Gaffarel, 21000 Dijon, France. Email: andre.ramon@chu-dijon.fr.

Background: In gout, several types of dual-energy computed tomography (DECT) artifacts have been described (nail bed, skin, beam hardening, submillimeter and vascular artifacts), which can lead to overdiagnosis. The objective of this study was to determine the optimal DECT settings for post processing in order to reduce the frequency of some common artifacts in patients with suspected gout.

Methods: Seventy-seven patients hospitalized for suspected gout (feet/ankles and/or knees) who received a DECT imaging were included (final diagnosis of 43 gout and 34 other rheumatic disorders). Different postprocessing settings were evaluated using Syngovia software: nine settings (R1 to R9) were evaluated with a combination of different ratio (1.28, 1.36 and 1.55) and attenuation coefficient (120, 150, $170 \mathrm{HU})$.

Results: Among the nine settings tested, the R2 setting (170 HU, ratio $=1.28)$ significantly reduced the presence of knee and foot/ankle artifacts compared to the standard R1 setting (85\% and 94\% decrease in beam hardening and clumpy artifacts in the ankle and foot, respectively $(\mathrm{P}<0.001)$; a decrease of $71 \%, 60 \%$ and $88 \%$ respectively of meniscal beam hardening, beam hardening and submillimeter artifacts in the knee $(\mathrm{P}<0.001)$. Compared to standard settings, the use of R2 settings decreased sensitivity [0.79 (95\% CI: 0.65, 0.88 ) versus 0.90 (95\% CI: $0.78,0.96)$ ] and increased specificity [0.86 (95\% CI: $0.71,0.93)$ versus 0.63 (95\% CI: 0.47, 0.77)] $(\mathrm{P}<0.001)$. Settings using an attenuation coefficient to $120 \mathrm{HU}$ and/or a ratio to 1.55 were all associated with a significant increasing of artifacts, especially clumpy and beam hardening artifacts.

Conclusions: Applying a ratio of 1.28 and a minimum attenuation of $170 \mathrm{HU}$ in DECT post-processing eliminates the majority of artifacts located in the lower limbs, particularly clumpy artifacts and beam hardening.

Keywords: Gout; artifacts; dual energy computed tomography; post-processing

Submitted Mar 22, 2021. Accepted for publication Jul 15, 2021.

doi: 10.21037/qims-21-321

View this article at: https://dx.doi.org/10.21037/qims-21-321 


\section{Introduction}

Gout, one of the most common inflammatory rheumatic conditions, is characterized by intra-articular or periarticular monosodium urate (MSU) deposits (1). The prevalence of gout, which is estimated at $0.9 \%$ in France (2), is increasing due to the aging of the population and dietary habits that have shifted towards foods which are richer in purines and fructose.

The gold standard for confirming a diagnosis of gout is based on the detection of MSU crystals under polarized light microscopy in synovial fluid aspirated from the patient's joint. However, joint puncture has certain limitations (sensitivity, inaccessible joint site) (3), may not be available in inter-critical gout, and remains poorly used in primary care practice (4). Imaging offers an alternative method to detect the presence of MSU crystals in such clinical situations (5). Among the existing imaging techniques, dual-energy computed tomography (DECT) has demonstrated over the last decade its ability to detect MSU crystals deposited in the soft tissue surrounding joints. The principle of DECT is based on the difference in $\mathrm{X}$-ray absorption between two given materials (e.g., calcium and MSU). The difference in attenuation between the two materials at two different energy levels (80 and $140 \mathrm{kV}$ ) makes it possible to determine the nature of the material being studied.

The American College of Rheumatology/European League Against Rheumatism gout task force acknowledged the good performance of DECT for the diagnosis of gout (6-9) by including it in the 2015 classification criteria (10). A meta-analysis based on 8 studies (510 patients/268 controls) found a sensitivity and specificity of 0.847 and 0.936 , respectively (11). DECT and ultrasound had comparable diagnostic performance (12). However, reproducibility is generally excellent in DECT, and better than for ultrasound $(6,13)$.

Nevertheless, not all material color coded as urate on DECT corresponds to locations of urate deposition. These artifacts, related to either the patient or the CT acquisition (14-17), can lead to an over-diagnosis of gout (false positives), but this issue has been insufficiently evaluated in patients with suspected gout.

Artifacts were defined in the 2015 ACR/EULAR criteria (10) as follows: nail bed deposits, skin deposits, beam hardening artifacts, submillimeter points [defined as "clumpy" artifacts in the ankle and foot (18)] and vascular and movement artifacts. Identification of the most common artifacts and artifact-reduction techniques are therefore essential for the radiologist to avoid overdiagnosis and the unnecessary implementation of urate-lowering therapy $(14,18)$.

Optimization of post-processing settings is an essential prerequisite for any imaging. For DECT, the increase or decrease of the attenuation coefficient (HU) has shown a decrease in some artifacts $(17,18)$. Increasing the range allows to smooth the image, making it possible to reduce certain artifacts, but at the cost of a reduction in spatial resolution. Modifying the post-processing parameters thus makes it possible to increase the volume of the MSU deposits (increase the range, decrease the minimum $\mathrm{HU}$ but at the cost of an increase in the frequency of artifacts) or, on the contrary, to reduce the artifacts but at the cost of a reduction in the volume of the "real" MSU deposits. It is therefore critical to find post-processing parameters that significantly reduce the occurrence of artifacts while maintaining the sensitivity of DECT for the detection of MSU deposits in patients suspected of gouty arthritis.

The aims of this study were to provide a descriptive analysis of the artifacts in gout patients and controls and to propose an optimization of the parameters during the postprocessing of the data in order to reduce the occurrence of artifacts in lower limb dual energy CT scan.

\section{Methods}

\section{Study design}

Retrospective, monocentric study conducted in the radiology and rheumatology departments of the Dijon University Hospital (France).

All consecutive patients hospitalized for suspicion of gouty arthritis who had a DECT exam of the lower limbs (feet/ankles and/or knees) from February 2015 to April 2020 were enrolled. The study was conducted in accordance with the Declaration of Helsinki (as revised in 2013). The study was approved by Institutional Review Board and individual consent for this study was waived.

\section{Collected data}

For each patient, demographic characteristics were collected. Cardiovascular comorbidities, serum urate level, gout duration, ultrasound findings for gout (presence of the double contour sign), radiographic data [Kellgren and Lawrence stage for knee osteoarthritis (19)] were 
also collected when available. A total of 102 patients underwent DECT scans for evaluation and quantification of their MSU crystal volume, but reconstructions from native sections were not possible for 25 patients who were therefore excluded from the analysis. Finally, 77 patients were included in the final analysis. Three patients had both ankle and knee DECT (80 DECT in total).

\section{Patient classification}

Patients were classified in the gout or non-gout group (other rheumatic disorders) according to the ACR 77 classification criteria (20) (results of joint puncture when performed or characteristics of the flare). The ACR/EULAR 2015 classification criteria were not used because they incorporate DECT data.

\section{DECT and post-processing}

The DECT used was a dual energy "dual source" scanner $(80 \mathrm{kV}-140 / \mathrm{Sn} \mathrm{kV})$ (SIEMENS, SOMATOM Flash definition). The acquisition time was $<2$ minutes per joint. Mean (SD) delivered radiation dose (DLP) for the knee was $203 \pm 27.8 \mathrm{mGy} \cdot \mathrm{cm}$ and for the ankle/foot $179 \pm 45.6 \mathrm{mGy} \cdot \mathrm{cm}$. The approximate effective radiation dose reported in other studies was $0.5 \mathrm{mSv}(21)$. The scanner was equipped with $2 \times 64$ detectors and $2 \times(64 \times 0.6 \mathrm{~mm})$ collimations. The number of reconstructed slices was $2 \times 128$ slices/turn. Concerning the "double energy lower extremity" protocol used, the rotation time was 0.5 seconds with a collimation of $0.32 \times 0.6 \mathrm{~mm}$. The post-processing of the data was performed using Syngo Via software (version Somaris/7 Syngo CT 2012 B, VH 10 ASL 79118 Siemens Healthineers). The standard parameters used during the acquisition were: ratio 1.36; $\mathrm{HU}$ minimum 150; $\mathrm{HU}$ maximum $500 \mathrm{HU}$; distance to air and distance to bone 5; range 4 .

\section{Image analysis}

All DECT images were read by experienced musculoskeletal radiologists and blinded to clinical-biological patient data and diagnosis.

In order to reduce the occurrence of artifacts and to define the most relevant parameters to be modified, different ratio settings were tested: $1.28,1.36$, and 1.55 $(22,23)$. Concerning the attenuation coefficient (HU), we systematically applied (in association with a ratio of 1.28 , 1.36 and 1.55 ) different settings, calibrating the minimum attenuation to $120 \mathrm{HU}, 150 \mathrm{HU}$ (default) and $170 \mathrm{HU}$.

Comparison between the nine different settings ("R1" 1.36-150 HU; "R2" 1.28-170 HU; "R3" 1.28-120 HU; "R4" 1.28-150 HU; "R5” 1.36-120 HU; "R6" 1.36-170 HU; "R7" 1.55-120 HU; "R8" 1.55-150 HU; "R9" 1.55-170 HU) was performed. The maximum attenuation (500 HU), the distance to air, the distance to bone and the range were not modified.

\section{Statistical analyses}

The inter-observer reproducibility of each examination was achieved by determining Cohen's kappa coefficient. Excellent reproducibility is indicated by kappa $>0.81$, good from 0.80 to 0.71 , moderate from 0.70 to 0.41 , poor from 0.40 to 0.21 , and very poor $<0.20$. No imputations were performed for missing data. Qualitative variables were compared using a Chi2 or Fisher's test when appropriate. Quantitative variables were compared using a Student's $T$-test or Mann Whitney test when appropriate. The frequencies of artifacts according to the different parameters applied were compared using a McNemar's test. A Friedman test was performed to compare volumes for matched populations. Correlations between the presence of the artifacts and clinical features (age, sex, high blood pressure, diabetes, BMI, and severe knee osteoarthritis and calcium pyrophosphate deposits for knee localization) were obtained with a Spearman's test. Diagnostic performance based on the calculation of sensitivity, specificity, positive predictive value, negative predictive value and ROC curve was then calculated for the standard settings and for all modified settings; all tests were considered significant if their $\mathrm{P}$ values were below 0.05 . Analyses were performed using IBM SPSS v25 statistics software.

\section{Results}

\section{Study population (Table 1)}

Of the 77 patients, 43 met ACR77 criteria for the diagnosis of gout. Among them, 26 had a joint puncture (16 knees and 10 ankle/feet). Joint fluid analysis found MSU crystals in 18 of these patients. For the remaining 34 patients, the diagnoses retained were: chondrocalcinosis $(n=9$; based on presence of calcium pyrophosphate (CPP) crystals on joint fluid analysis), osteoarthritis flare-up ( $\mathrm{n}=18$; based on $\mathrm{X}$-ray results and/or cytology of joint fluid aspiration), and other chronic inflammatory rheumatic diseases $(n=7$; rheumatoid 
Table 1 Clinical-biological and DECT characteristics of the gout and non-gout groups

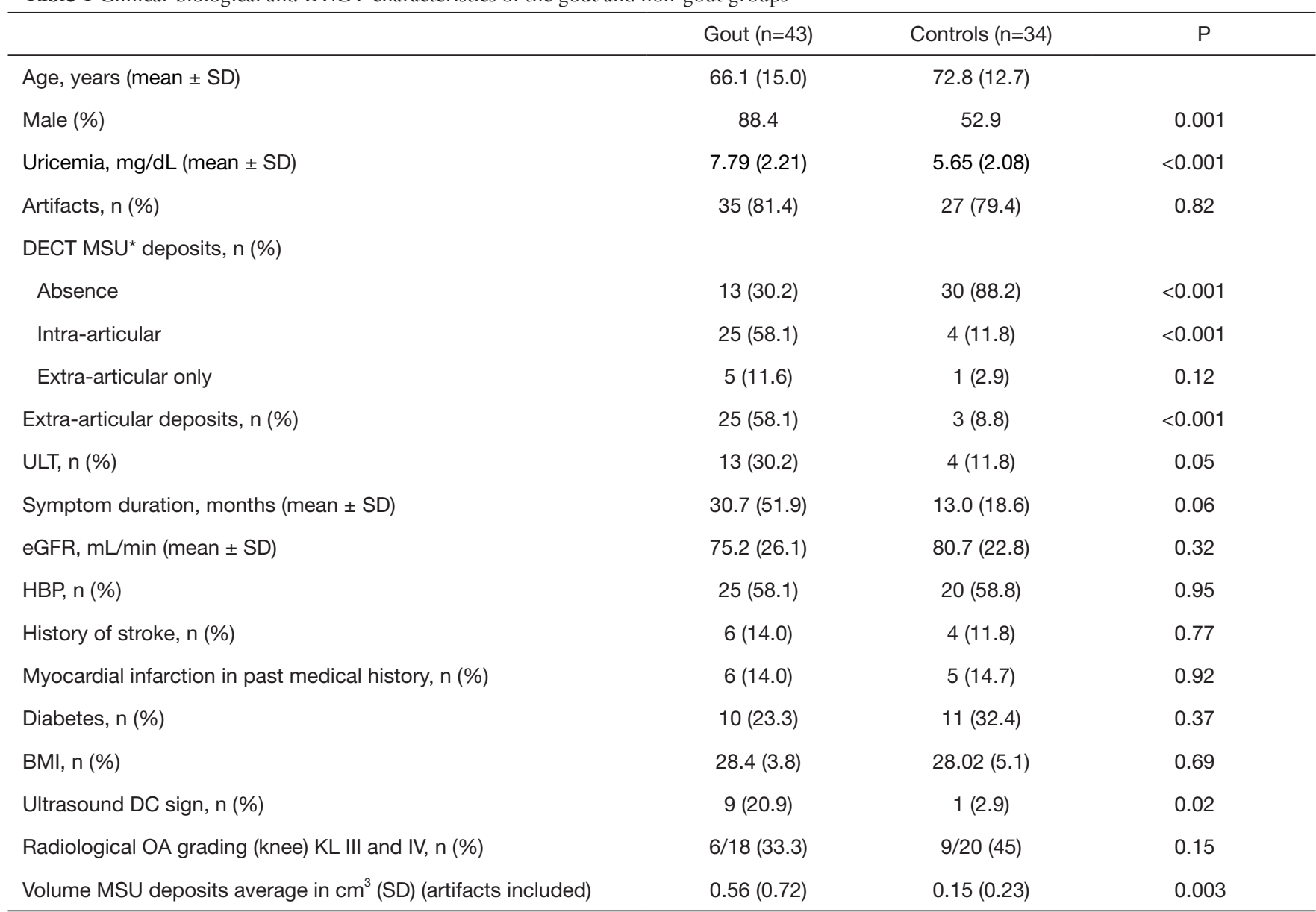

Osteoarticular ultrasound was performed on 59 of 77 patients $(76.7 \%$ of cases) looking for the double contour sign. Quantitative values are expressed as a mean ( \pm standard deviation SD). Significance: $\mathrm{P}<0.05$. *, Artifacts excluded. MSU, monosodium urate; ULT, urate-lowering therapy; HBP, high blood pressure; DC, double contour sign; KL, Kellgren and Lawrence radiological grading, severe for stages 3 and 4; BMI, body mass index $\left(\mathrm{kg} / \mathrm{m}^{2}\right)$; eGFR, estimated glomerular filtration rate (CKD-EPI).

arthritis, ankylosing spondylarthritis, psoriatic arthritis). Patient characteristics are presented in Table 1.

\section{Diagnostic performance of R1 to R9 settings (Table 2 and Figures S1-S3)}

Diagnostic performance of each setting was calculated separately for each location (ankle/foot and knees) and for combination of both ("full").

Best diagnostic performance was obtained with the R2 settings [AUC foot/ankle $=0.81(\mathrm{P}<0.001)$; AUC knee $=0.89(\mathrm{P}<0.001) ;$ AUC "foot/ankle + knee $=0.84(\mathrm{P}<0.001)]$. However, the use of R2 settings decreased sensitivity [0.79 (95\% CI: $0.65,0.88)$ versus 0.90 (95\% CI: $0.78,0.96)]$ and increased specificity [0.86 (95\% CI: $0.71,0.93)$ versus 0.63
(95\% CI: $0.47,0.77)$ ] compared to $\mathrm{R} 1$ settings $(\mathrm{P}<0.001)$. Settings using $120 \mathrm{HU}$ attenuation coefficients were all associated to an increase of artifacts especially clumpy and beam hardening artifacts.

\section{Foot and ankle artifacts (42 DECT) (Table 3 and Table S1)}

For inter-observer reproducibility of artifacts identification (using default "R1" settings), kappa coefficients were calculated and showed good to excellent reproducibility: Nail bed: kappa $=1.00$ (95\% CI: 1.00, 1.00), skin: kappa $=0.90$ (95\% CI: 0.73, 1.00), clumpy: kappa $=0.81$ (95\% CI: $0.63,0.99)$, beam hardening: kappa $=0.84(95 \% \mathrm{CI}: 0.65$, $0.95)$.

The application of "R2" settings in post-processing 
Table 2 Diagnostic performance from R1 (standard setting) to R9 (modified setting) in ankle/foot, knee DECT and the combination of both locations ("full")

\begin{tabular}{|c|c|c|c|c|c|}
\hline & Sensitivity $(95 \% \mathrm{Cl})$ & Specificity (95\% Cl) & PPV (95\% Cl) & NPV (95\% Cl) & AUC \\
\hline R1 knee & $1.00(0.82,1.00)$ & $0.55(0.34,0.74)$ & $0.66(0.55,0.76)$ & $1.00(1.00,1.00)$ & $0.77(0.62,0.93)$ \\
\hline R2 ankle/foot & $0.69(0.50,0.83)$ & $0.93(0.72,0.98)$ & $0.94(0.72,0.99)$ & $0.65(0.50,0.77)$ & $0.81(0.68,0.94)$ \\
\hline R2 knee & $0.94(0.74,0.99)$ & $0.85(0.63,0.91)$ & $0.85(0.64,0.91)$ & $0.94(0.74,0.99)$ & $0.89(0.78,1.00)$ \\
\hline R3 knee & $1.00(0.82,1.00)$ & NC & $0.47(0.32,0.62)$ & $\mathrm{NC}$ & $0.50(0.31,0.69)$ \\
\hline R4 ankle/foot & $0.81(0.62,0.91)$ & $0.44(0.23,0.66)$ & $0.70(0.52,0.83)$ & $0.58(0.31,0.80)$ & $0.62(0.44,0.80)$ \\
\hline R4 knee & $1.00(0.82,1.00)$ & $0.40(0.22,0.61)$ & $0.60(0.42,0.75)$ & $1.00(0.67,1.00)$ & $0.7(0.53,0.87)$ \\
\hline R5 ankle/foot & $1.00(0.87,1.00)$ & $\mathrm{NC}$ & $0.61(0.47,0.75)$ & $\mathrm{NC}$ & $0.50(0.32,0.69)$ \\
\hline R6 knee & $1.00(0.82,1.00)$ & $0.35(0.18,0.56)$ & $0.58(0.41,0.73)$ & $1.00(0.64,1.00)$ & $0.67(0.50,0.85)$ \\
\hline R7 ankle/foot & $1.00(0.62,1.00)$ & NC & $0.61(0.47,0.75)$ & NC & $0.50(0.32,0.69)$ \\
\hline R7 knee & $1.00(0.82,1.00)$ & $\mathrm{NC}$ & $0.47(0.32,0.62)$ & $\mathrm{NC}$ & $0.50(0.31,0.69)$ \\
\hline R8 ankle/foot & $0.93(0.75,0.97)$ & $0.14(0.01,0.28)$ & $0.61(0.45,0.75)$ & $0.33(0.06,0.79)$ & $0.49(0.31,0.67)$ \\
\hline R8 knee & $1.00(0.82,1.00)$ & NC & $0.47(0.32,0.62)$ & NC & $0.50(0.31,0.69)$ \\
\hline R9 ankle/foot & $0.96(0.81,0.99)$ & $0.19(0.06,0.43)$ & $0.65(0.49,0.78)$ & $0.75(0.30,0.95)$ & $0.57(0.39,0.76)$ \\
\hline R9 knee & $1.00(0.82,1.00)$ & NC & $0.47(0.32,0.62)$ & NC & $0.50(0.31,0.69)$ \\
\hline R1 "full" & $0.90(0.78,0.96)$ & $0.63(0.47,0.77)$ & $0.75(0.66,0.82)$ & $0.85(0.68,0.93)$ & $0.77(0.66,0.88)$ \\
\hline
\end{tabular}

R1 setting =ratio 1.36; $\mathrm{HU}=150$; bone distance =5; air distance =5; range =4; R2 setting =ratio 1.28; $\mathrm{HU}=170$; bone distance =5; air distance =5; range =4; R3 setting=ratio 1.28; $\mathrm{HU}=120$; bone distance =5; air distance =5; range =4; $\mathrm{R} 4$ setting=ratio 1.28; $\mathrm{HU}=150$; bone distance =5; air distance =5; range =4; R5 setting=ratio 1.36; $\mathrm{HU}=120$; bone distance =5; air distance =5; range =4; R6 setting=ratio 1.36; $\mathrm{HU}=170$; bone distance =5; air distance =5; range =4; R7 setting=ratio 1.55; $\mathrm{HU}=120$; bone distance =5; air distance =5; range =4; $\mathrm{R} 8$ setting=ratio 1.55; $\mathrm{HU}=150$; bone distance =5; air distance =5; range =4; R9 setting=ratio 1.55; $\mathrm{HU}=170$; bone distance =5; air distance =5; range $=4$. PPV, positive predictive value; NPV, negative predictive value; $95 \% \mathrm{Cl}, 95 \%$ confidence interval; NC, non calculated. "full" $=$ ankle/foot + knee.

Table 3 Comparison of the frequency of different ankle and/or foot artifacts according to the standard setting (R1) and the modified setting R2 and R3 $(n=42)$

\begin{tabular}{|c|c|c|c|c|}
\hline & $\mathrm{R} 1$ & $\mathrm{R} 2$ & $\mathrm{R} 3$ & $\mathrm{P}$ \\
\hline Nail bed n (\%) & $30(71.4)$ & $24(57.1)$ & $31(73.8)$ & $<0.001$ \\
\hline Skin n (\%) & $6(14.3)$ & $1(2.4)$ & $11(26.2)$ & $<0.001$ \\
\hline Beam hardening $\mathrm{n}(\%)$ & $14(33.3)$ & $2(4.8)$ & $17(40.5)$ & $<0.001$ \\
\hline
\end{tabular}

$\mathrm{R} 1$ is the standard setting (ratio at 1.36 and minimum attenuation set to $150 \mathrm{HU}$ ). R2 is the modified setting (ratio at 1.28 and minimum attenuation set to $170 \mathrm{HU}$ ). R3 is the standard setting (ratio at 1.28 and minimum attenuation set to $120 \mathrm{HU}$ ). SD, standard deviation. Significance: $\mathrm{P}<0.05$. 

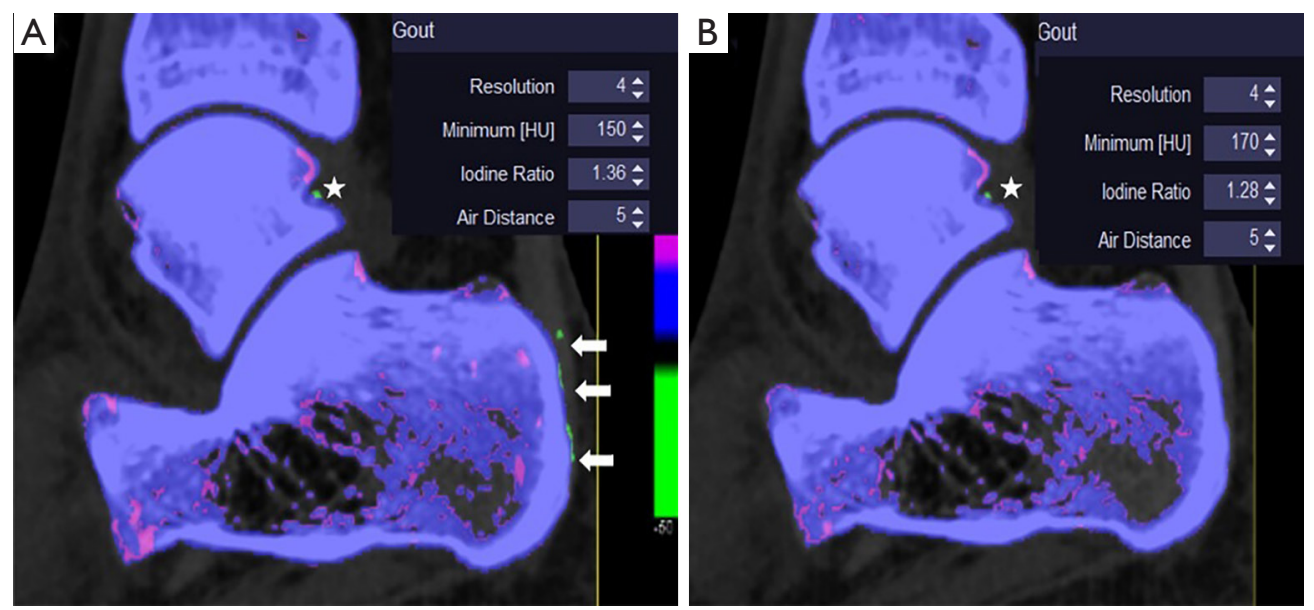

Figure 1 Ankle sagittal view. Beam hardening artifact (arrows) (calcaneum) (A) with a talus gout deposition. Application of "R2" settings led to artifact removal (arrows). Note the persistence of a pathological deposit of MSU on the posterior aspect of the talus at setting R2 (asterisk). (A) R1 settings (150 HU, ratio 1.36); (B) R2 settings (170 HU, ratio 1.28).

significantly reduced almost all the described ankle and foot artifacts. Nail bed artifacts were reduced by $20 \%$, skin artifacts by $83.3 \%$, beam hardening by $85.6 \%$, and submillimeter artifacts by $94.1 \%$ (Figure 1). However, the application of the "R2" settings (170 HU, ratio 1.28) was accompanied by a significant decrease in total MSU volume (reduced by 58.7\%) (Table 3, Figure 2).

The application of the "R3" setting with ratio of 1.28 and minimum attenuation of $120 \mathrm{HU}$ found a significant increase in the volume of MSU deposits [mean R1 vs. mean $\mathrm{R} 3$; $0.33 \pm 0.50$ vs. $0.94 \pm 0.95 \mathrm{~cm}^{3}(\mathrm{P}<0.001)$ ], a significant increase in the occurrence of clumpy artifacts (increased by $129 \%$ ) and a non-significant increase in the frequency of skin artifacts, beam hardening and nail beds (Table 3). The results of "R4" to "R9" settings are summarized in Table S1. No correlations were found between foot/ankle artifacts and clinical features (Table S2).

\section{Knee artifacts (38 DECT) (Table 4 and Table S3)}

Kappa coefficients for inter-reader reproducibility showed moderate to good reproducibility: meniscal beam hardening: kappa $=0.77$ (95\% CI: 0.54, 0.94), beam hardening: kappa $=0.78$ (95\% CI: 0.56, 0.99), submillimeter artifacts: kappa $=0.67$ (95\% CI: 0.47, 0.83), vascular artifacts: kappa $=0.63$ (95\% CI: $0.25,0.92)$. The application of R2 settings in post-processing significantly reduced the set of artifacts defined by the ACR/ EULAR 2015 criteria (Figures 3,4). Meniscal beam hardening artifacts were reduced by $71 \%$, beam hardening by $60 \%$, submillimeter artifacts by $88.9 \%$, and vascular artifacts by $100 \%$. However, the application of the "R2" setting resulted in a significant reduction in the volume of MSU deposits, as in the ankle/foot area (volume reduced by 60\%) (Table 4).

In contrast, application of R3 settings significantly increased meniscal beam hardening artifacts (38\%) and essentially clumpy artifact (300\%). The results of "R4" to "R9" settings are summarized in Table S3.

The presence of articular chondrocalcinosis $(n=9)$ was significantly associated with the occurrence of meniscal beam hardening artifacts (Spearman's Rho $\sigma=0.501 ; 95 \%$ CI: 0.307, 0.666; $\mathrm{P}=0.001)$. Similarly, BMI was associated with the occurrence of beam hardening artifacts (excluding menisci) in the knee $(\sigma=0.430 ; 95 \%$ CI: $0.09,0.668$; $\mathrm{P}=0.007)$ (Table S4).

\section{Discussion}

The aim of this case-control study in a real-life setting was to optimize DECT post-processing parameters in order to reduce the frequency of some artifacts commonly occurring in DECT performed for gout assessment. According to our results, lowering the ratio to 1.28 and increasing the minimum attenuation to $170 \mathrm{HU}$ could eliminate artifacts that interfere with the proper interpretation of the DECT, and thus reduce the risk of false positives by radiologists.

This adjustment of the ratio and attenuation coefficient settings showed a gain in specificity (from $63.9 \%$ to $86.1 \%$ ) at the expense of sensitivity, which dropped from $90.9 \%$ 

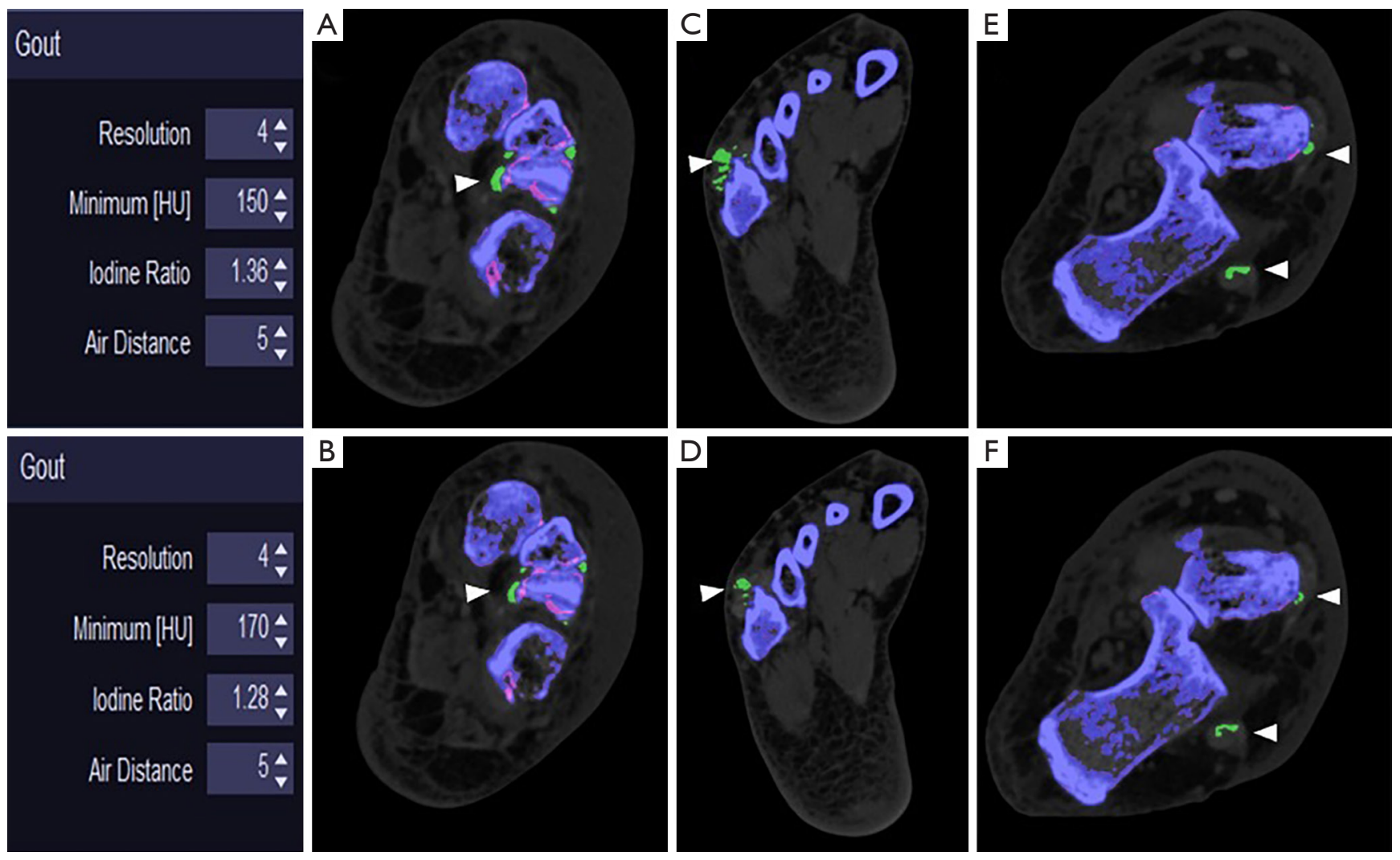

Figure 2 DECT axial section of ankle and foot. The application of "R2" settings showed a decrease in MSU deposit volume (head of arrow) $(\mathrm{B}, \mathrm{D}, \mathrm{F})$ in comparison to standard settings "R1" (A,C,E).

Table 4 Comparison of the frequency of different knee artifacts according to the standard setting (R1) and the modified setting (R2) (n=38)

\begin{tabular}{|c|c|c|c|c|}
\hline & $\mathrm{R} 1$ & $\mathrm{R} 2$ & R3 & $\mathrm{P}$ \\
\hline Average MSU volume $\mathrm{cm}^{3}$ (SD) & $0.42(0.64)$ & $0.17(0.35)$ & $0.82(0.97)$ & $<0.001$ \\
\hline Meniscal beam hardening, $\mathrm{n}(\%)$ & $21(55.3)$ & $6(15.8)$ & $29(76.3)$ & $<0.001$ \\
\hline Beam hardening, $\mathrm{n}(\%)$ & $25(65.8)$ & $10(26.3)$ & $25(65.8)$ & $<0.001$ \\
\hline Clumpy, n (\%) & $9(23.7)$ & $1(2.6)$ & $36(94.7)$ & $<0.001$ \\
\hline
\end{tabular}

$\mathrm{R} 1$ is the standard setting (ratio at 1.36 and minimum attenuation set to $150 \mathrm{HU}$ ). R2 is the modified setting (ratio at 1.28 and minimum attenuation set to $170 \mathrm{HU}$ ). R3 is the modified setting (ratio at 1.28 and minimum attenuation set to $120 \mathrm{HU}$ ). SD, standard deviation. Significance: $\mathrm{P}<0.05$.

to $79.5 \%$. The initial specificity $(63.5 \%)$ is lower than what has been reported in previous DECT studies, but the studied populations are not comparable. Indeed, most of the authors who found specificity $>80 \%$ were studying patients with a known diagnosis of long-lasting and severe gout. In patients with undifferentiated arthritis, Gamala et al. (24) found that DECT had a lower specificity $(<60 \%)$, close to our results.

Despite the R2 settings (ratio 1.28 and $170 \mathrm{HU}$ ), the most common artifacts (14) such as nail bed deposits and subcutaneous artifacts persist, but they are generally easily identifiable by MSK radiologists. As extra-articular manifestation of gout are common on DECT imaging, it seems particularly important to minimize the clumpy 

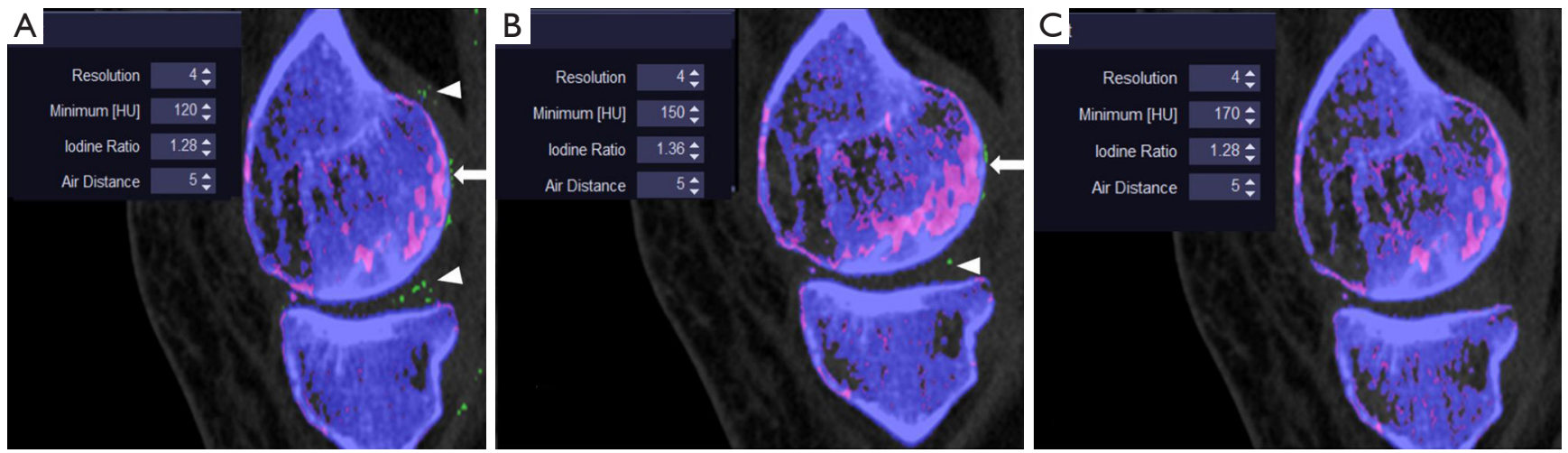

Figure 3 Sagittal knee sections in DECT in a "non-gout" patient. (A) Enhancement of the beam hardening (arrows) and submillimiter artifacts (head of arrows) using the R3 settings; (B) presence of beam hardening (arrows) and submillimeter artifacts (head of arrows) with standard settings (R1); (C) absence of artifacts with setting $\mathrm{R} 2$ (HU=170; ratio =1.28).
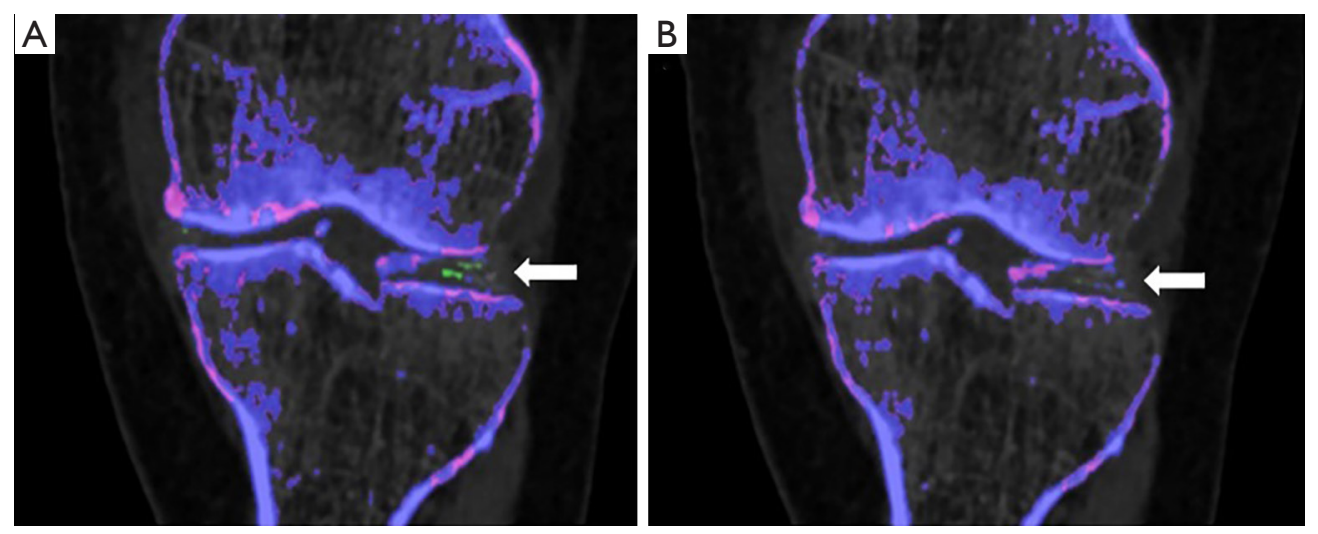

Figure 4 Coronal view of meniscal beam hardening artifact (arrow) (A) with standard settings "R1" (ratio: 1.36, HU=150). (B) Artifact removal with application of "R2" settings (ratio 1.28, HU=170). Joint puncture demonstrated presence of multiple calcium pyrophosphate crystals with no evidence of MSU crystals.

artifacts that appear within tendons and ligaments in the foot and ankle and also meniscal artifacts. In routine practice they are easily confused with actual urate deposits within these fibro-cartilage structures. Another effective method to eliminate or reduce clumpy artifacts is the use of tin filter, as reported by Park et al. (18) and Jeon et al. (25). Nevertheless, in our experience, clumpy artifacts may persist despite the tin filter.

In order to optimize the post-processing parameters, Park et al. (18) suggested increasing the minimum attenuation from 130 to $150 \mathrm{HU}$. The application of these parameters makes it possible to decrease the frequency of some artifacts. The authors also found a significant decrease $(\mathrm{P}<0.007)$ in the volume of MSU deposits, which is also the case in our cohort. This limitation needs to be considered because attempting to optimize the specificity of the DECT in gout can reduce its sensitivity, as demonstrated again. Our results show a significant decrease in MSU volume using the "R2" setting compared to the "R1" setting (Tables 3,4). Despite this decrease in MSU volume, it appears that most of the large MSU deposits may remain (Figure 2). Nevertheless, in the case of minimal deposits, the use of these parameters on DECT may lead to a risk of false negatives for the diagnosis of gout. However, the tophaceous volume alone is probably not sufficient to explain the disappearance of R2 deposits, as the density of the deposits is likely to also play a role (26).

According to our results, submillimeter artifacts are significantly reduced or even eliminated in most cases by the settings retained (ratio at $1.28 ; H U=170$ ). It appears 
that decreasing the ratio reduced beam hardening artifacts, and decreasing the attenuation coefficient reduced clumpy artifacts. These observations may be explained by tissue attenuation principle that depends on the density (Zeff) of tissue and $\mathrm{X}$-ray beam energy $(\mathrm{KeV})$. Indeed, trabecular bone, meniscal CPP deposits and UMS deposits have close densities (at 80 and $140 \mathrm{kV}$ ). Decrease the ratio allows to a better differentiation between calcium deposits (CPP and trabecular bone) and MSU deposits. On the contrary, increasing ratio do not allow to distinguish between them and lead to false green coloration deposits (meniscal CPP deposits).

The settings used in this study proved to be effective for the ankle and foot but also for the knee, which had not been reported until now. It is also of interest to use the same parameters for these two-common locations of gouty arthritis, taking into account that it is usual practice to request a DECT of the knee and ankle for the evaluation of suspected gout. Other studies have shown the interest of modifying other parameters in post-processing in order to reduce artifacts. Mallinson et al. (14) noted that reducing the distance to air and the distance to bone reduced subcutaneous and under-nail bed artifacts. These different parameters were not tested in our study because these common artifacts are quite simple to identify and remove in routine imaging practice.

Another study looked at the post-processing parameters of DECT data in typical gout disease (involvement of first metatarsophalangeal joint) (27). The application of a minimum attenuation at $120 \mathrm{HU}$ would allow a better visualization of the MSU deposits and a better correlation in terms of volume with ultrasound. Indeed, DECT tends to underestimate the volume of a tophus by visualizing only the "crystalline" part, unlike ultrasound which also takes into account the adjacent soft parts (28). In our experience, the application of these parameters does not seem to be relevant to the rest of the foot, the ankle, and the knee, because it leads to a significant increase in noise that hinders interpretation (clumpy artifacts especially).

It appears that some artifacts are not very sensitive to post-processing modifications, such as artifacts related to metallic materials and movement artifacts. In these cases, the best way to limit these artifacts would be either to modify the parameters during image acquisition (modification of the rotation speed of the slats, use of specific kernel, tin filter, etc.) $(14,15)$, or to ensure the correct positioning of the patient (29).

We recognize that this study has some limitations, including the recruitment in a single university center and the low number of patients. The use of ACR 77 classification criteria can be an important limitation. Indeed, there is a risk that some patients classified as "controls" might have gout, notably in cases of short duration of the condition.

Another fundamental aspect for the better detection of artifacts is the identification of patient-related risk factors. Our results identified certain factors associated with the occurrence of knee artifacts, including the significant correlation between beam hardening artifacts and BMI value, which has not been reported previously. One possible explanation for the correlation between BMI and beam hardening artifact could be that the increase of soft tissue (with an increase of density) lead to beam hardening. Another possibility is be that cortical bone is thicker in patients with a high BMI (maybe due to higher mechanical strains) than in subjects with a normal BMI.

Similarly, a correlation was found between the frequency of meniscal beam hardening artifacts and articular chondrocalcinosis in the knee. On the other hand, and contrary to the hypothesis of Bongartz et al. (7), no correlation was found between the existence of severe knee osteoarthritis (stage 3 and 4 of Kellgren and Lawrence) and the presence of meniscal beam hardening artifacts. Our result could nevertheless be partly explained by a lack of power of the present study, which remains to be confirmed.

In conclusion, we confirmed the high frequency of artifacts in DECT for the evaluation of suspected gout. Artifact-reduction techniques are therefore essential for mitigating their occurrence and misinterpretation. Indeed, the application of a ratio of 1.28 and a minimum attenuation of $170 \mathrm{HU}$ makes it possible to eliminate some DECT artifacts in the foot, ankle and knee joints, with a significant gain in specificity. Nevertheless, the application of R2 parameters results in a drop in sensitivity, especially for foot/ankle, which can be a limitation for these localizations. Further advances in DECT acquisition and post-processing techniques are necessary to increase the accuracy of this second-line diagnostic approach in cases where the diagnosis is uncertain.

\section{Acknowledgments}

We thank Suzanne Rankin from the Dijon University Hospital for proofreading the article.

Funding: None. 


\section{Footnote}

Conflicts of Interest: All authors have completed the ICMJE uniform disclosure form (available at https://dx.doi. org/10.21037/qims-21-321). TP received research grants from Horizon Pharmaceuticals and personal fees for consulting and lectures by Novartis. Romaric Loffroy serves as an unpaid deputy editor of Quantitative Imaging in Medicine and Surgery. The other authors have no conflicts of interest to declare.

Ethical Statement: The authors are accountable for all aspects of the work in ensuring that questions related to the accuracy or integrity of any part of the work are appropriately investigated and resolved. The study was conducted in accordance with the Declaration of Helsinki (as revised in 2013). The study was approved by Institutional Review Board and individual consent for this study was waived.

Open Access Statement: This is an Open Access article distributed in accordance with the Creative Commons Attribution-NonCommercial-NoDerivs 4.0 International License (CC BY-NC-ND 4.0), which permits the noncommercial replication and distribution of the article with the strict proviso that no changes or edits are made and the original work is properly cited (including links to both the formal publication through the relevant DOI and the license). See: https://creativecommons.org/licenses/by-nc-nd/4.0/.

\section{References}

1. Dalbeth N, Choi HK, Joosten LAB, Khanna PP, Matsuo H, Perez-Ruiz F, Stamp LK. Gout. Nat Rev Dis Primers 2019;5:69.

2. Bardin T, Bouée $S$, Clerson P, Chalès G, Flipo RM, Lioté F, Perez V, Poiraud T, Schaeverbeke T, Richette P. Prevalence of Gout in the Adult Population of France. Arthritis Care Res (Hoboken) 2016;68:261-6.

3. Segal JB, Albert D. Diagnosis of crystal-induced arthritis by synovial fluid examination for crystals: lessons from an imperfect test. Arthritis Care Res 1999;12:376-80.

4. Owens D, Whelan B, McCarthy G. A survey of the management of gout in primary care. Ir Med J 2008;101:147-9.

5. Richette P, Doherty M, Pascual E, Barskova V, Becce F, Castaneda J, et al. 2018 updated European League Against Rheumatism evidence-based recommendations for the diagnosis of gout. Ann Rheum Dis 2020;79:31-8.

6. Choi HK, Burns LC, Shojania K, Koenig N, Reid G, Abufayyah M, Law G, Kydd AS, Ouellette H, Nicolaou S. Dual energy CT in gout: a prospective validation study. Ann Rheum Dis 2012;71:1466-71.

7. Bongartz T, Glazebrook KN, Kavros SJ, Murthy NS, Merry SP, Franz WB 3rd, Michet CJ, Veetil BM, Davis JM 3rd, Mason TG 2nd, Warrington KJ, Ytterberg SR, Matteson EL, Crowson CS, Leng S, McCollough CH. Dual-energy CT for the diagnosis of gout: an accuracy and diagnostic yield study. Ann Rheum Dis 2015;74:1072-7.

8. Diekhoff T, Ziegeler K, Feist E, Kiefer T, Mews J, Hamm

B, Hermann KG. First experience with single-source dualenergy computed tomography in six patients with acute arthralgia: a feasibility experiment using joint aspiration as a reference. Skeletal Radiol 2015;44:1573-7.

9. Lee SK, Jung JY, Jee WH, Lee JJ, Park SH. Combining non-contrast and dual-energy CT improves diagnosis of early gout. Eur Radiol 2019;29:1267-75.

10. Neogi T, Jansen TL, Dalbeth N, Fransen J, Schumacher HR, Berendsen D, et al. 2015 Gout classification criteria: an American College of Rheumatology/European League Against Rheumatism collaborative initiative. Ann Rheum Dis 2015;74:1789-98.

11. Lee YH, Song GG. Diagnostic accuracy of dual-energy computed tomography in patients with gout: A metaanalysis. Semin Arthritis Rheum 2017;47:95-101.

12. Gruber M, Bodner G, Rath E, Supp G, Weber M, Schueller-Weidekamm C. Dual-energy computed tomography compared with ultrasound in the diagnosis of gout. Rheumatology (Oxford) 2014;53:173-9.

13. Terslev L, Gutierrez M, Christensen R, Balint PV, Bruyn GA, Delle Sedie A, et al. Assessing Elementary Lesions in Gout by Ultrasound: Results of an OMERACT Patientbased Agreement and Reliability Exercise. J Rheumatol 2015;42:2149-54.

14. Mallinson PI, Coupal T, Reisinger C, Chou H, Munk PL, Nicolaou S, Ouellette H. Artifacts in dual-energy CT gout protocol: a review of 50 suspected cases with an artifact identification guide. AJR Am J Roentgenol 2014;203:W103-9.

15. Coupal TM, Mallinson PI, Gershony SL, McLaughlin PD, Munk PL, Nicolaou S, Ouellette HA. Getting the Most From Your Dual-Energy Scanner: Recognizing, Reducing, and Eliminating Artifacts. AJR Am J Roentgenol 2016;206:119-28.

16. Garner HW, Wessell DE. Gout: Update on Dual-Energy Computed Tomography with Emphasis on Artifact 
Identification. Curr Rheumatol Rep 2018;20:86.

17. Abdellatif W, Ding J, Khorshed D, Shojania K, Nicolaou S. Unravelling the mysteries of gout by multimodality imaging. Semin Arthritis Rheum 2020;50:S17-23.

18. Park EH, Yoo WH, Song YS, Byon JH, Pak J, Choi Y. Not All Green Is Tophi: The Importance of Optimizing Minimum Attenuation and Using a Tin Filter to Minimize Clumpy Artifacts on Foot and Ankle Dual-Energy CT. AJR Am J Roentgenol 2020;214:1335-42.

19. Kohn MD, Sassoon AA, Fernando ND. Classifications in Brief: Kellgren-Lawrence Classification of Osteoarthritis. Clin Orthop Relat Res 2016;474:1886-93.

20. Wallace SL, Robinson H, Masi AT, Decker JL, McCarty DJ, Yü TF. Preliminary criteria for the classification of the acute arthritis of primary gout. Arthritis Rheum 1977;20:895-900.

21. Henzler T, Fink C, Schoenberg SO, Schoepf UJ. Dualenergy CT: radiation dose aspects. AJR Am J Roentgenol 2012;199:S16-25.

22. Nicolaou S, Yong-Hing CJ, Galea-Soler S, Hou DJ, Louis L, Munk P. Dual-energy CT as a potential new diagnostic tool in the management of gout in the acute setting. AJR Am J Roentgenol 2010;194:1072-8.

23. McQueen FM, Doyle AJ, Reeves Q, Gamble GD, Dalbeth N. DECT urate deposits: now you see them, now you don't. Ann Rheum Dis 2013;72:458-9.

24. Gamala M, Jacobs JWG, Linn-Rasker SF, Nix M, Heggelman BGF, Pasker-de Jong PCM, van Laar JM, Klaasen R. The performance of dual-energy CT in the

Cite this article as: Dubief B, Avril J, Pascart T, Schmitt M, Loffroy R, Maillefert JF, Ornetti P, Ramon A. Optimization of dual energy computed tomography post-processing to reduce lower limb artifacts in gout. Quant Imaging Med Surg 2022;12(1):539-549. doi: 10.21037/qims-21-321 classification criteria of gout: a prospective study in subjects with unclassified arthritis. Rheumatology (Oxford) 2020;59:845-51.

25. Jeon JY, Lee SW, Jeong YM, Baek HJ. The effect of tube voltage combination on image artefact and radiation dose in dual-source dual-energy CT: comparison between conventional $80 / 140 \mathrm{kV}$ and $80 / 150 \mathrm{kV}$ plus tin filter for gout protocol. Eur Radiol 2019;29:1248-57.

26. Christiansen SN, Müller FC, Østergaard M, Slot O, Møller JM, Børgesen HF, Gosvig KK, Terslev L. Dualenergy CT in gout patients: Do all colour-coded lesions actually represent monosodium urate crystals? Arthritis Res Ther 2020;22:212.

27. Strobl S, Kremser C, Taljanovic M, Gruber J, Stofferin H, Bellmann-Weiler R, Klauser AS. Impact of DualEnergy CT Postprocessing Protocol for the Detection of Gouty Arthritis and Quantification of Tophi in Patients Presenting With Podagra: Comparison With Ultrasound. AJR Am J Roentgenol 2019;213:1315-23.

28. Pascart T, Grandjean A, Norberciak L, Ducoulombier V, Motte M, Luraschi H, Vandecandelaere M, Godart C, Houvenagel E, Namane N, Budzik JF. Ultrasonography and dual-energy computed tomography provide different quantification of urate burden in gout: results from a crosssectional study. Arthritis Res Ther 2017;19:171.

29. Ramon A, Pottecher P, Ornetti P. Gout misdiagnosis due to dual-energy computed tomography artefact. Rheumatology (Oxford) 2018;57:1234. 


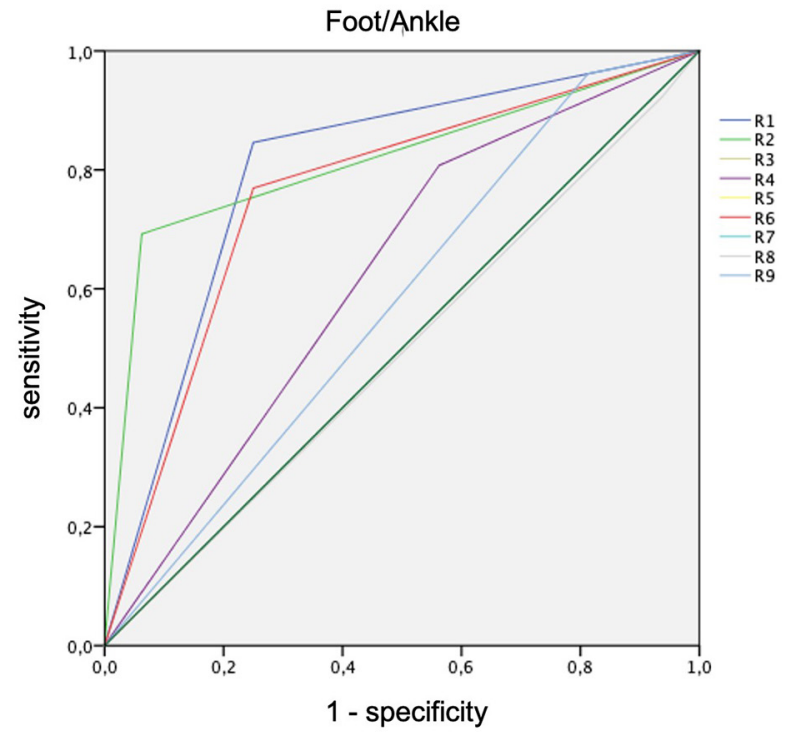

\begin{tabular}{|cccc|}
\hline Setting & AUC & $p$ & $95 \% \mathrm{Cl}$ \\
\hline R1 & 0.78 & 0.001 & $(0.65 ; 0.95)$ \\
R2 & 0.81 & 0.001 & $(0.68 ; 0.94)$ \\
R3 & 0.50 & 1.00 & $(0.32 ; 0.69)$ \\
R4 & 0.62 & 0.18 & $(0.44 ; 0.80)$ \\
R5 & 0.50 & 1.00 & $(0.32 ; 0.69)$ \\
R6 & 0.76 & 0.005 & $(0.60 ; 0.92)$ \\
R7 & 0.50 & 1.00 & $(0.32 ; 0.69)$ \\
R8 & 0.49 & 0.93 & $(0.31 ; 0.67)$ \\
\hline R9 & 0.57 & 0.42 & $(0.39 ; 0.76)$ \\
\hline
\end{tabular}

AUC: area under the curve; $95 \% \mathrm{Cl}: 95 \%$ confidence interval Significance: $\mathrm{P}<0.05$

Figure S1 Comparative analysis of diagnostic performance from R1 to R9 settings for foot/ankle [ROC and area under the curve (AUC)]. 


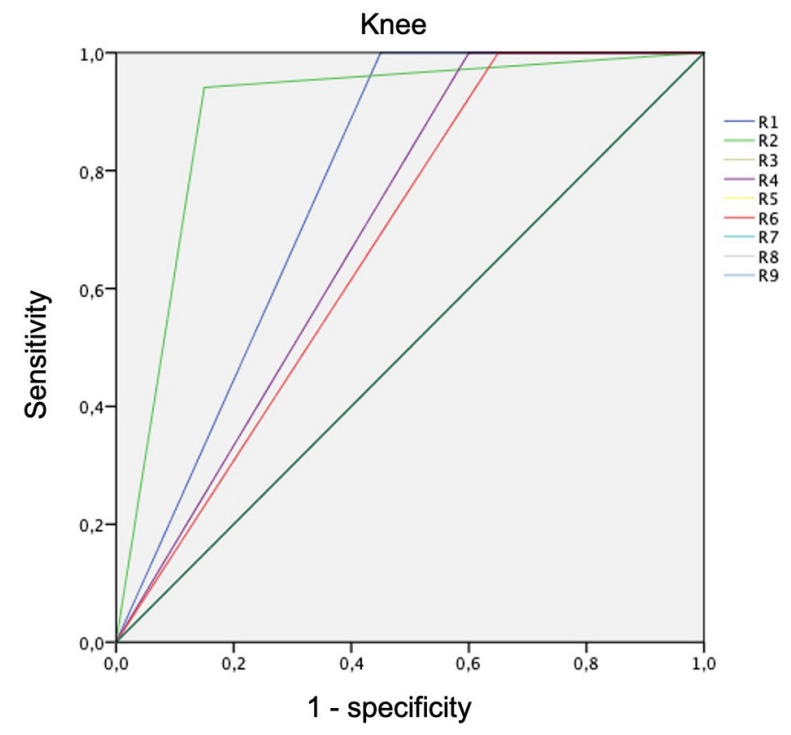

\begin{tabular}{|cccc|}
\hline Setting & AUC & $p$ & $95 \% \mathrm{Cl}$ \\
\hline R1 & 0.77 & 0.004 & $(0.62 ; 0.93)$ \\
\hline R2 & 0.89 & $<0.001$ & $(0.78 ; 1.00)$ \\
\hline R3 & 0.50 & 1.00 & $(0.31 ; 0.69)$ \\
\hline R4 & 0.70 & 0.03 & $(0.53 ; 0.87)$ \\
\hline R5 & 0.50 & 1.00 & $(0.31 ; 0.69)$ \\
\hline R6 & 0.67 & 0.07 & $(0.50 ; 0.85)$ \\
\hline R7 & 0.50 & 1.00 & $(0.31 ; 0.69)$ \\
R8 & 0.50 & 1.00 & $(0.31 ; 0.69)$ \\
\hline R9 & 0.50 & 1.00 & $(0.31 ; 0.69)$ \\
\hline
\end{tabular}

AUC: area under the curve; $95 \% \mathrm{Cl}: 95 \%$ confidence interval Significance: $\mathrm{P}<0.05$

Figure S2 Comparative analysis of diagnostic performance from R1 to R9 settings for knee [ROC and area under the curve (AUC)]. 


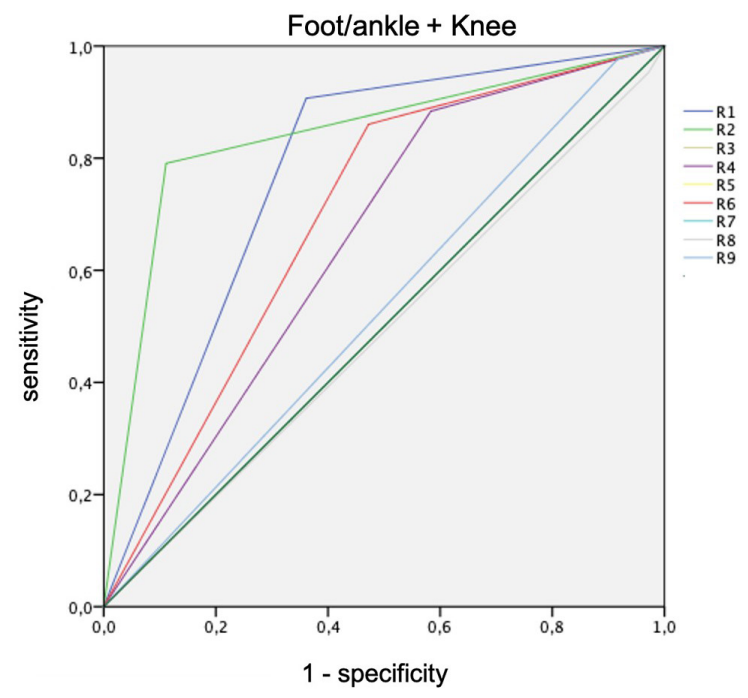

\begin{tabular}{|cccc} 
Setting & AUC & $p$ & $95 \% \mathrm{Cl}$ \\
\hline R1 & 0.77 & $<0.001$ & $(0.66 ; 0.88)$ \\
R2 & 0.84 & $<0.001$ & $(0.75 ; 0.93)$ \\
R3 & 0.50 & 1.00 & $(0.37 ; 0.62)$ \\
R4 & 0.65 & 0.02 & $(0.52 ; 0.77)$ \\
R5 & 0.50 & 1.00 & $(0.37 ; 0.62)$ \\
R6 & 0.69 & 0.003 & $(0.57 ; 0.81)$ \\
R7 & 0.50 & 1.00 & $(0.37 ; 0.62)$ \\
R8 & 0.49 & 0.88 & $(0.36 ; 0.61)$ \\
R9 & 0.53 & 0.64 & $(0.40 ; 0.66)$
\end{tabular}

AUC: area under the curve; $95 \% \mathrm{Cl}: 95 \%$ confidence interval Significance: $\mathrm{P}<0.05$

Figure S3 Comparative analysis of diagnostic performance from R1 to R9 settings for foot/ankle + knee [ROC and area under the curve $(\mathrm{AUC})]$. 
Table S1 Comparison of the frequency of different ankle and/or foot artifacts according to the R1 to R9 settings ( $\mathrm{n}=42$ )

\begin{tabular}{lccccccccccc}
\hline & $\mathrm{R} 1$ & $\mathrm{R} 2$ & $\mathrm{R} 3$ & $\mathrm{R} 4$ & $\mathrm{R} 5$ & $\mathrm{R} 6$ & $\mathrm{R} 7$ & $\mathrm{R} 8$ & $\mathrm{R} 9$ \\
\hline Nail bed n (\%) & $30(71.4)$ & $24(57.1)$ & $31(73.8)$ & $23(54.7)$ & $28(66.6)$ & $21(50.0)$ & $29(69.0)$ & $28(66.6)$ & $26(61.9)$ & $<0.001$ \\
Skin n (\%) & $6(14.3)$ & $1(2.4)$ & $11(26.2)$ & $3(7.1)$ & $7(16.6)$ & $2(4.7)$ & $7(16.6)$ & $4(9.5)$ & $2(4.7)$ & $<0.001$ \\
Beam hardening n (\%) & $14(33.3)$ & $2(4.8)$ & $17(40.5)$ & $6(14.2)$ & $13(30.9)$ & $5(11.9)$ & $42(100)$ & $38(90.4)$ & $34(80.9)$ & $<0.001$ \\
Clumpy n (\%) & $17(40.5)$ & $1(2.4)$ & $39(92.9)$ & $10(23.8)$ & $37(88.1)$ & $1(2.3)$ & $40(95.2)$ & $6(14.2)$ & $1(2.3)$ & $<0.001$ \\
Average volume of & $0.33(0.50)$ & $0.13(0.25)$ & $0.94(0.95)$ & $0.26(0.40)$ & $1.18(1.08)$ & $0.20(0.36)$ & $2.57(1.93)$ & $1.00(1.17)$ & $0.67(0.92)$ & $<0.001$ \\
MSU Cm ${ }^{3}$ (SD) & & & & & & & & & & &
\end{tabular}

SD, standard deviation. Significance: $P<0.05$.

Table S2 Correlation between most common artifacts and clinical features for the foot/ankle

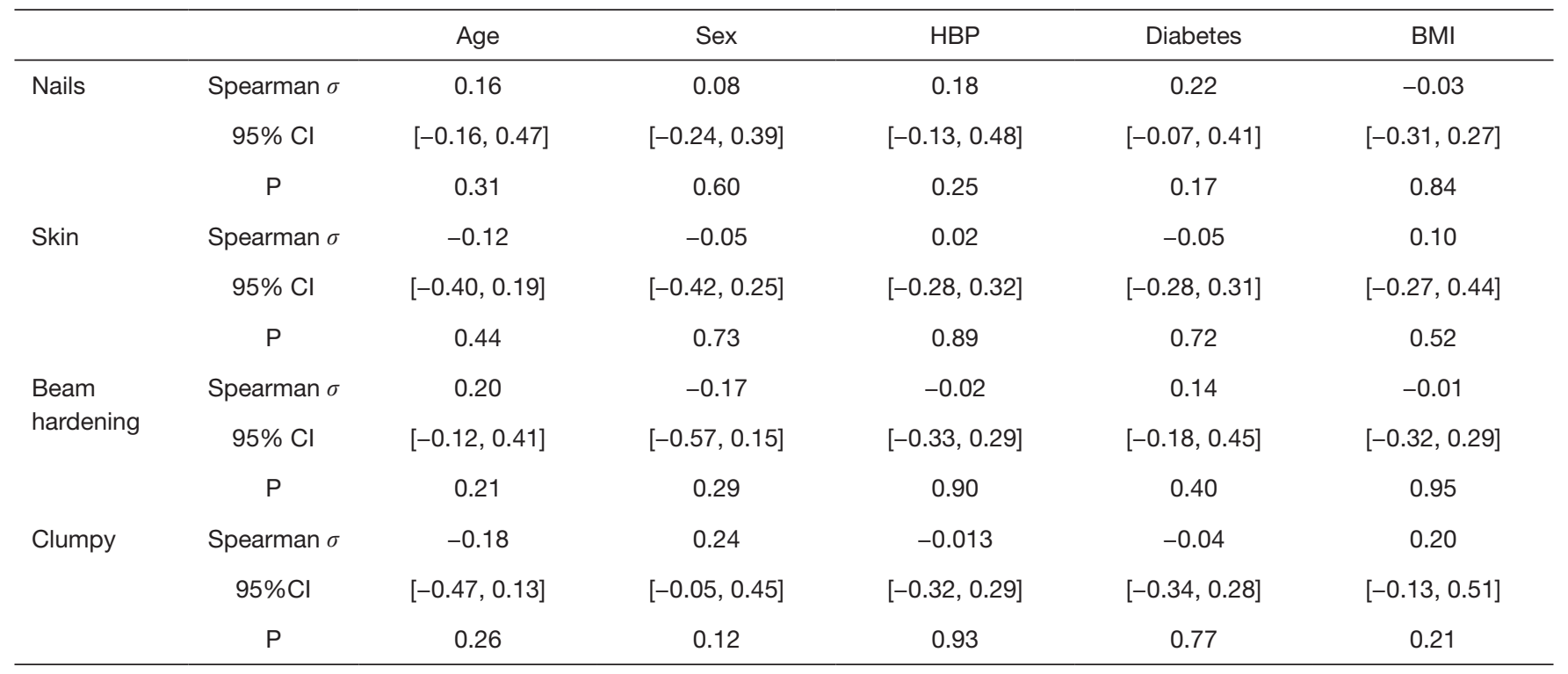

HBP, high blood pressure; BMI, body mass index; 95\% Cl: 95\% confidence interval. Significance: $\mathrm{P}<0.05$. 
Table S3 Comparison of the frequency of different knee artifacts according to the R1 to R9 settings ( $\mathrm{n}=38$ )

\begin{tabular}{lcccccccccc}
\hline & $\mathrm{R} 1$ & $\mathrm{R} 2$ & $\mathrm{R} 3$ & $\mathrm{R} 4$ & $\mathrm{R} 5$ & $\mathrm{R} 6$ & $\mathrm{R} 7$ & $\mathrm{R} 8$ & $\mathrm{R} 9$ & $\mathrm{P}$ \\
\hline $\begin{array}{l}\text { Meniscal beam } \\
\text { hardening n (\%) }\end{array}$ & $21(55.3)$ & $6(15.8)$ & $29(76.3)$ & $16(42.1)$ & $30(78.9)$ & $15(39.5)$ & $33(86.8)$ & $20 /(52.6)$ & $19(50)$ & $<0.001$ \\
Beam hardening n (\%) & $25(65.8)$ & $10(26.3)$ & $25(65.8)$ & $15(39.5)$ & $27(71.1)$ & $17(44.7)$ & $38(100)$ & $38(100)$ & $38(100)$ & $<0.001$ \\
Clumpy n (\%) & $9(23.7)$ & $1(2.6)$ & $36(94.7)$ & $4(10.5)$ & $38(100)$ & $3(7.9)$ & 38 & $6(15.8)$ & $0(0)$ & $<0.001$ \\
Vascular n (\%) & $7(18.4)$ & $0(0)$ & $8(21.1)$ & $2(5.3)$ & $7(18.4)$ & $3(7.9)$ & $14(36.8)$ & $9(23.7)$ & $9(23.7)$ & $<0.001$ \\
$\begin{array}{l}\text { Average volume of } \\
\text { MSU, } \mathrm{cm}^{3} \text { (SD) }\end{array}$ & $0.42(0.64)$ & $0.17(0.35)$ & $0.82(0.97)$ & $0.28(0.54)$ & $1.12(1.17)$ & $0.24(0.42)$ & $3.21(2.16)$ & $1.64(1.31)$ & $1.17(0.95)$ & $<0.001$ \\
\hline
\end{tabular}

Table S4 Correlation between most common artifacts and clinical features for the knee

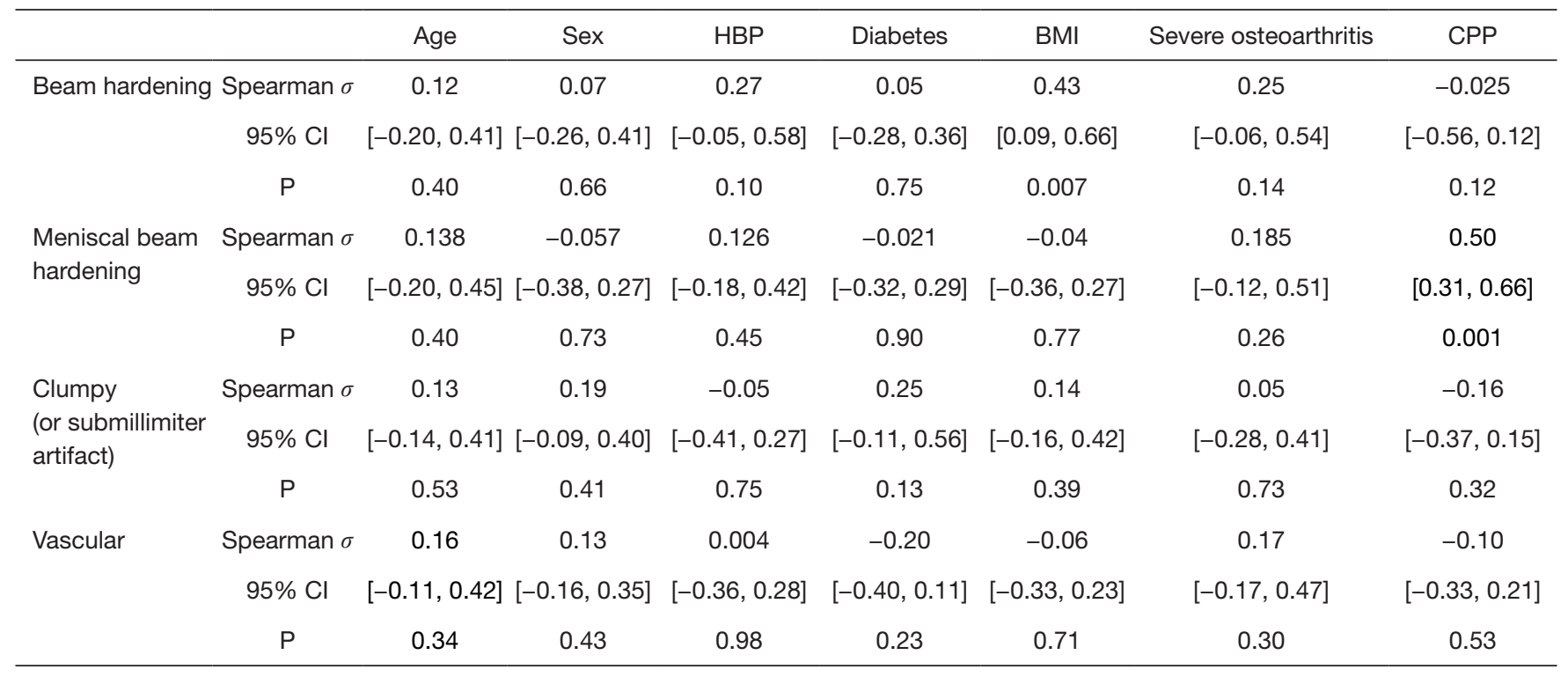

HBP, high blood pressure; BMI, body mass index; CPP, Calcium Pyrophosphate deposits; 95\% Cl: 95\% confidence interval. Significance: $\mathrm{P}<0.05$. 

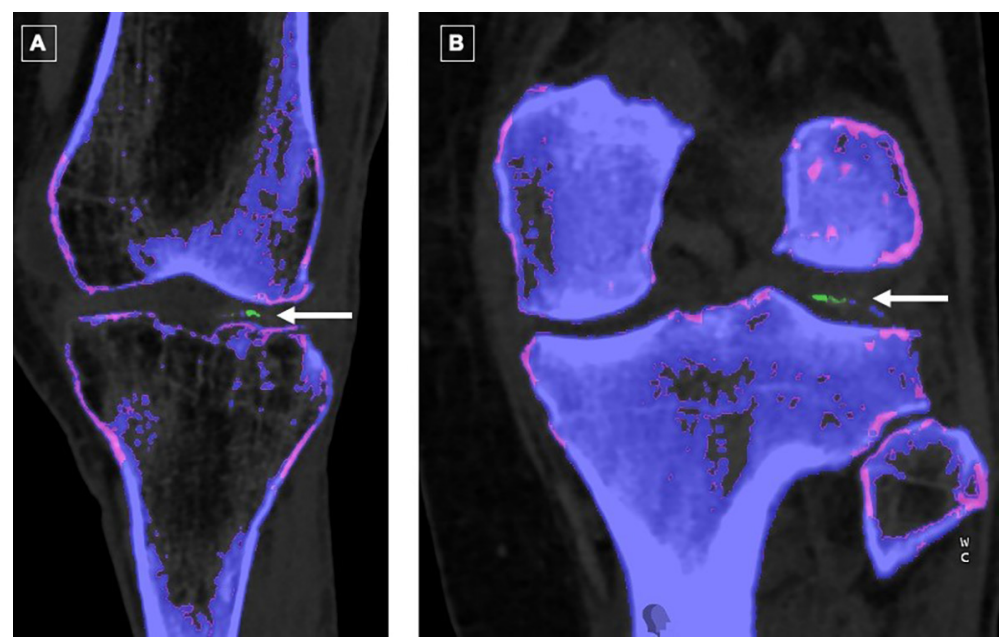

Illustration of meniscal beam hardening artifact in knee (image A and B) (arrows).
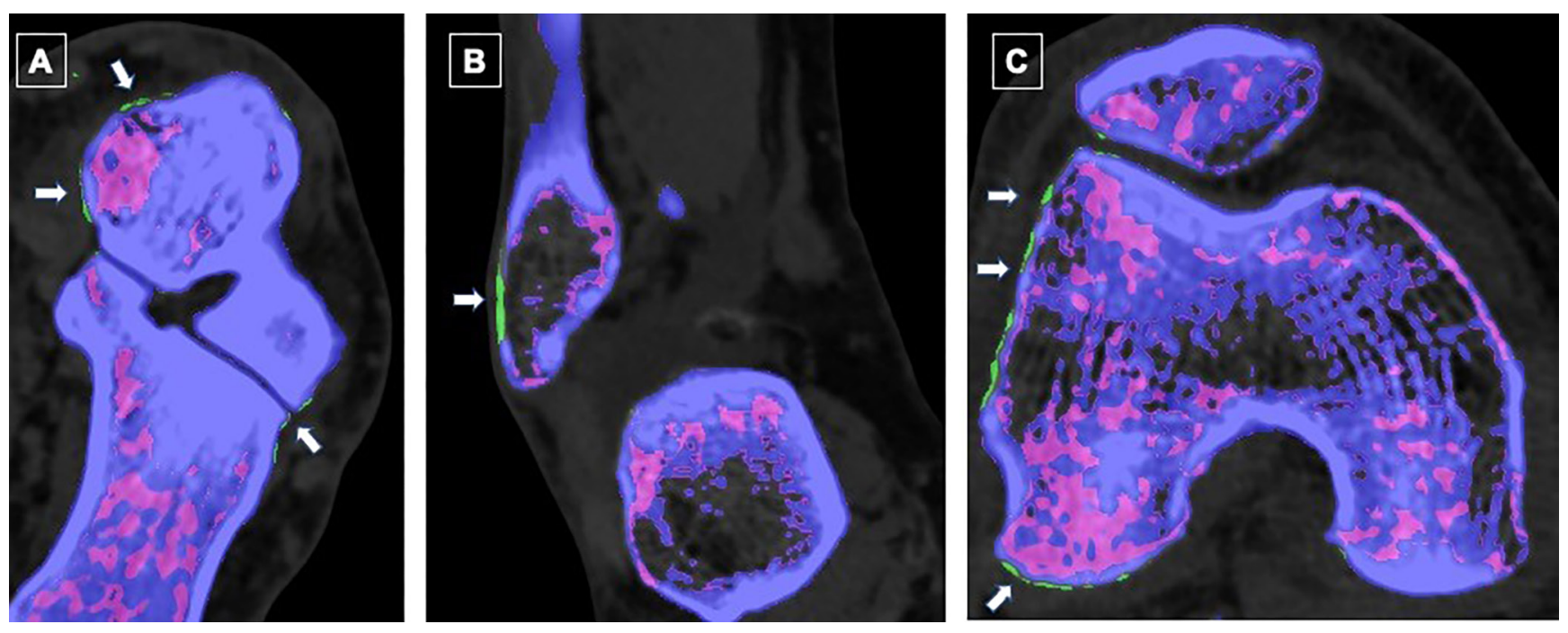

Illustration of beam hardening artifact in ankle (A, B) and knee (C) (arrows). Beam hardening follows the path of the hardened beam and was seen mainly within cortical bone. The beam hardening artifact was defined by a linear green deposit following cortical bone. 